\title{
LETTERS / LETTRES
}

\section{Comments on Editorial}

I wish to comment on the rather eristic editorial written by Brendan Hemens in the November/December 2000 Issue of The Forestry Chronicle.

There are three important flaws in the thinking, along with many lesser transgressions, in Mr. Hemens' editorial. First, marten are often used as a surrogate, or indicator, for old forest species in New Brunswick, and elsewhere in eastern Canada. The management expression may be the specific maintenance of marten habitat, but it refers to maintaining biodiversity associated with old forest systems. Although biodiversity is more than a species list, other species also prefer old forests, including many lichen species, boreal owls, long-eared bats, various beetles, hover flies, red crossbills, black-backed woodpeckers, brown creepers, three-toed woodpeckers, and so on. The theory (which remains to be tested and hence the precaution) is that if we effectively maintain sufficient old forest in time and space on a landscape for marten, all of the other attributes $\exists$ and species in old forest systems will also remain present and functioning. So marten may be the specified objective, but keeping old forest attributes is the goal. In the New Brunswick case, the target only implicitly involves marten, but specifically refers to old forests. The objective is not reservation, but rather maintenance of the qualities, communities, and characteristics of biological diversity that occur only in old conifer-dominated and mixed woods forests.

Second, and even more incorrect, is the assumption that because marten use younger than predicted second-growth forests in Maine: 1) this is the optimal habitat for the marten, and 2) the research results are transportable globally. Wrong on both counts. In Newfoundland, the endangered marten subspecies relies almost exclusively on old forests for breeding and hunting. Information from Ontario clearly showed that, while marten can and do live in young forests, they are subjected to much higher rates of mortality than they suffered in old forests, making the younger habitats obviously less than optimal. The Maine situation is interesting, but I suspect that Baxter State Park has a lot to do with survivorship of the species in young forest habitats. Home range sizes reported from Maine are almost double what they are in boreal old forest habitats in Ontario, which are even less productive. Home range size is an excellent predictor of habitat quality and breeding success, suggesting that marten in Maine are "making do" with poor-quality habitat, rather than flourishing in optimal habitat. Over the long term, it is unlikely that a species can persist in suboptimal habitat without a source population, and history is replete with examples of extinctions where species existed for long periods in remnant degraded habitats, before finally disappearing. The management objectives, with evolutionary theory and historical precedent in mind, should be to maintain optimal habitats for species, not simply habitats where they might survive.

Third, Hemens takes a rather pedantic position about science, apparently thinking that progress is instantaneous, and further suggesting that scientists simply disregard research that they do not like. The sword can cut both ways, so following Mr. Hemens' logic, we should argue that the Maine researchers were clearly bought off by industry and have disregarded earlier research because it didn't fit their model. However, an alternative explanation might be that scientists are more cautious than Mr. Hemens would like, preferring instead to evaluate critically the evidence, searching for possible pitfalls, rather than simply applying each new result as a universal gospel truth. Ecological systems are not so simple that cause and effect is easily and universally derived, and idiosyncratic results are more common than general ones.

It would appear that the precautionary principle is not well-explained to forestry students at UNB, for it has little to do with emotion and considerable to do with history. Timber harvesting is, at best, an experiment in ecology, the results of which will not ultimately be seen for many more years. The grand assumption is that forest management is benign. We should not need the carcasses of extinct species to tell us to be careful in using socalled renewable resources. Atlantic cod and Atlantic salmon are only two of many recent examples of species declines, where application of the precautionary principle would have helped. Although people seem to want overnight results these days, extinction usually is a longterm event. It is important to keep the perspective that industry has only operated in North America for a few hundred years, and that our growth rate has only recently become exponential. It is highly probable that timber harvesting may have already had immutable effects on some species that will ultimately lead to their extinction, but probably only over the next 50 or 100 years.

Therefore, current policies that may err on the side of caution are indeed prudent. Even so, forest land-use changes in the northeastern USA have resulted in the extinction of four forest bird species (Pimm et al. 1995. Science 269: 347-350). These represent $16 \%$ of the only 26 endemic bird species over $<400$ years; an extinction rate consistent with that globally predicted for areas where humans have caused habitat loss. Other eastern Canadian vertebrate species (or populations) will likely follow, including marten in Newfoundland and Cape Breton. This should be sufficient warning. It is irresponsible and naive to assume that we have used our forests wisely simply because some species haven't yet gone extinct.

\section{Ian Thompson Research Scientist}

\section{Brendan Hemens Replies}

I thank Dr. Thompson for his informed, interesting, and earnest reply. I want to briefly address some of his points, and clarify some of mine.

As the indicator species that once had the largest perceived need of contiguous old growth habitat, I maintain that the amount and spatial quality of area preserved in an old forest condition is indeed based primarily on outdated estimates of marten requirements.

However, the use of marten in my editorial was something of a red herring, and I recognize Dr. Thompson's compelling arguments as valid concerns. I believe he misinterpreted the heart of my argument. I did not intend to suggest that scientific progress is instantaneous, nor that researchers are a shady and devious lot, manufacturing evidence as they see fit. Rather, I hold to a classic notion of 
science as impartial observation, strictly so, where researchers attempt to disprove their expectations to the point of erring on the side of rejection, rather than arrive at a false conclusion.

The Newfoundland marten sub-species that Dr. Thompson identifies has had a few thousand years to develop the genetic distinction he credits them with, not even a blink of an eye on an evolutionary scale. Could this really be the root cause of their apparently different habitat use, or could some other factor be responsible? Like the passenger pigeon, one of the four birds Pimm et al. (1995) refer to, I suspect habitat loss is a partial and proximate cause of population decline, and that attention would be better directed towards activities responsible for the direct loss of threatened individuals, such as hunting and trapping. Maine, with a viable population of marten, the most forest of any US state, and the longest history of timber harvesting of any state, seems to indicate that harvesting itself is benign, while farming, urban sprawl, and hunting activity are the real threats.

Dr. Thompson, history is also replete with habitat studies where researchers only looked for subject animals where they expected to find them. Lists of species presumed extinct change on an annual basis as specimens are re-discovered. Two decades ago, E.O. Wilson suggested that 40000 species a year go extinct due to timber harvesting activity. Since then, approximately 1 million species should have disappeared from the earth forever. Can Dr. Thompson name five? As Dr. Thompson points out, endemic species are especially vulnerable to habitat loss. Unfortunately for them, they have always been so. When researchers like Pimm et al. (1995) compare the historic extinction rates of widespread, abundant marine species based on incomplete palaeontological evidence with those of narrowly endemic rare species measured in a modern context, they massage scientific evidence to conform with their opinions.

The precautionary principle is simply good risk management. I do not reject it, but I reject its use in the support of scientific conclusions. It is up to forest stakeholders with a management prerogative to take objective scientific evidence, and apply it to their decisions with appropriate caution.
I am sure Dr. Thompson's erroneous (if not eristic) remark concerning education at UNB was tongue-in-cheek. Nonetheless, in deference to my instructors and with respect for my fellow students, I note that my opinion is my own and not necessarily representative of anyone else at this institution. I thank my professors and fellow students for encouraging an atmosphere supportive of intellectual debate, and for spending much time with me over the years examining the different facets of many forestry issues.

Brendan Hemens, Student, UNB

\section{Special Thanks to the Canadian Institute of Forestry}

The University of Alberta Forest Society, representing Forestry students of the past, present, and future, would like to thank the Canadian Institute of Forestry for its many years of support.

Graduates of this program value the welcome into the profession and the symbolism of the common interest of forestry granted by the Silver Ring Ceremony. Since the first graduating class of 1974, all University of Alberta Forestry graduates have received a silver ring that bears a significant bond between members of the forestry profession. Attendance by Canadian Institute of Forestry members and the executive at the graduation ceremony is an anticipated networking opportunity.

Students in every year of the program look forward to the opportunity to attend technical sessions and appreciate the subscription to the Forestry Chronicle at an affordable rate. The technical sessions and journal articles are a valuable resource for paper writing, supplemental information, and interest.

Forestry students at the University of Alberta consider the Canadian Institute of Forestry to be an integral part of the program. This is not taken for granted and we look forward to an ongoing relationship.

\section{Come visit CIF/IFC at http://www.cif-ifc.org}

read about CIF/IFC activities \& Section News

find Working Group contacts

read CIF/IFC Position Papers

learn about Continuing Education Opportunities

explore Job Opportunities

become a member

view links to other sites

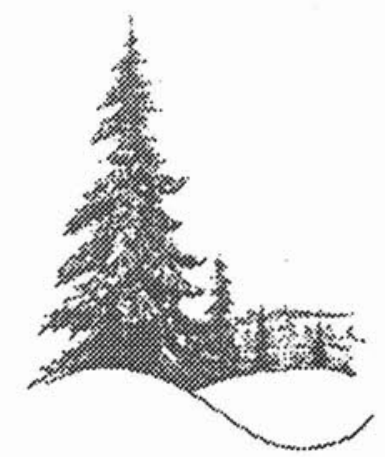

